\title{
The most problematic variable in the course of human-biometeorological comfort assessment - the mean radiant temperature
}

Research Article

\author{
Noémi Kántor*, János Unger \\ Department of Climatology and Landscape Ecology, \\ University of Szeged, \\ POBox. 653, 6701, Szeged, Hungary
}

Received 21 November 2010; accepted 4 March 2011

\begin{abstract}
This paper gives a review on the topic of the mean radiant temperature $\mathrm{T}_{m r t}$, the most important parameter influencing outdoor thermal comfort during sunny conditions. $\mathrm{T}_{m r t}$ summarizes all short wave and long wave radiation fluxes reaching the human body, which can be very complex (variable in spatial and also in temporal manner) in urban settings. Thermal comfort researchers and urban planners need easy and sound methodological approaches to assess $T_{m r t}$. After the basics of the $T_{m r t}$ calculation some of the methods suitable for obtaining $T_{m r t}$ also in urban environments will be presented.. Two of the discussed methods are based on instruments which measure the radiation fluxes integral (globe thermometer, pyranometer-pyrgeometer combination), and three of the methods are based on modelling the radiation environment with PC software (RayMan, ENVI-met and SOLWEIG).
\end{abstract}

Keywords: mean radiant temperature $\cdot$ definition $\cdot$ calculation $\cdot$ measurement $\cdot$ modelling

(C) Versita Sp. z o.o.

\section{Introduction}

One of the most studied areas in human-biometeorology - which deals with the combined effects of atmospheric conditions on the human organism - focuses on the assessment of the thermal environment. The meteorological parameters of air temperature, air humidity, wind velocity and thermal (infrared) radiation are described as thermal factors and have a thermo-physiological effect on the human heat balance and consequently on the state of human

*E-mail: sztyepp@gmail.com or kantor.noemi@geo.u-szeged.hu thermal comfort. In order to give a comprehensive humanbiometeorological evaluation, it is necessary to consider all of the meteorological parameters which affect the heat exchange between the human body and its (indoor or outdoor) environment [1-6].

From the point of view of thermal comfort, conductive heat transfer usually plays a non-significant role. On the contrary, convective ways of heat exchange are more important. Convective fluxes of sensible heat and latent heat are influenced by air temperature and air humidity, respectively, and both of them are affected by wind velocity. Measurement of these thermal factors does not cause any problem in general. The radiant environment has also a considerable effect on the body's heat balance; more- 
over, in the case of strong direct solar radiation it becomes the most significant agent of heat gain. However, the radiation field may be very complex, consisting of several long and short wave components. In order to summarize the effects of all radiant heat fluxes reaching the body the mean radiant temperature $\left(T_{m r t}\right)$ has become a very popular parameter in the field of human-biometeorology. Determination of this index is quite complicated in practice, especially in urban environments with diverse surface morphology.

The aim of this study is to give a review on the $T_{m r t}$ in a way which would be helpful, principally for the scientists who are new in the field of human-biometeorological thermal comfort assessments and also the outsiders who are not so familiar with this topic. Firstly, the definition of mean radiant temperature and the basics of its calculation are provided in a comprehensive overview, with illustrations explaining the theoretical background and using symbols and abbreviations adopted from the basic literature in this field $[4,6-8]$. Secondly, some of the existing methods which are applied most often to measure or to model this parameter outdoors are presented.

\section{Definition of the mean radiant temperature $\mathbf{T}_{m r t}$}

In the outdoor environment, the radiant energy transfer (heat loss or gain by thermal radiation) is the most important heat flux for the human heat balance, mainly in sunny conditions. The mean radiant temperature $T_{m r t}\left[{ }^{\circ} \mathrm{C}, \mathrm{K}\right]$ has been introduced in order to parameterize the effects of the complex radiant environment (containing several long and short wave radiation fluxes) in one, temperature-dimension index $[1,6]$. The mean radiant temperature, in relation to a given person placed in a given environment, in a given body posture and clothing, is defined as that uniform temperature of a fictive black-body radiation enclosure (emission coefficient $\epsilon=1$ ) which would result in the same net radiation energy exchange with the subject as the actual, more complex radiation environment (Fig. 1). The radiation fluxes vary considerably in open spaces compared to indoor situations, and in sunny conditions $\mathrm{T}_{m r t}$ can be more than $30^{\circ} \mathrm{C}$ higher than air temperature, while indoors they are approximately equal.

Regarding the $T_{m r t}$, the following radiation components are of great importance:

1. solar or short wave radiation reaching the lower atmosphere (wave length $\lambda=0.3-3 \mu \mathrm{m}$ )

(a) I - direct solar radiation

(b) D - diffuse solar radiation (c) $\mathrm{R}$ - reflected short wave radiation (parts of direct and diffuse solar radiation reflected from the ground and other surrounding surfaces)

2. terrestrial or long wave radiation (wave length $\lambda=$ 3-100 $\mu \mathrm{m})$

(a) A - atmospheric counter radiation (thermal radiation from the $\mathrm{sky}$ )

(b) $\mathrm{E}$ - long wave radiation of the environment (thermal radiation from the ground and other surrounding surfaces) $[4,6,7,9,10]$.

The relative significance of solar and terrestrial fluxes reaching the body from different directions related to $T_{m r t}$ depends on the time of the day and the year as well as the location. The night time radiation exchange consists exclusively of long wave components; the short wave irradiance has a role only during the sunlight hours and its importance increases with the altitude of the Sun. On a clear summer day thermal stress is mostly attributable to solar exposure, providing that the sky is unobstructed. However, in urban environments the radiation energy absorbed by a standing man is derived mainly from the long wave domain and less than $30 \%$ results from solar radiation in the daytime [11].

The above listed parameters are illustrated on Fig. 1 and included in Table 1 which contains all of the radiation fluxes significant for calculating $\mathrm{T}_{m r t}$ and the corresponding elements of the human radiation budget.

\section{Calculation of the $\mathbf{T}_{m r t}$}

To calculate the mean radiant temperature, the dimensions of the radiating surrounding surfaces, including the visible section of the sky have to be determined. Moreover, all revelant properties from the point of view of thermal radiation (e.g. emissivity, albedo) should be added. The body posture is also important, because the $T_{m r t}$ for a standing person is not the same as for a seated one. As $\mathrm{T}_{m r t}$ varies from point to point and also for the same point with the orientation of the body, the subject's location and orientation in the real environment must also be known. The absorbance of the outer surface of the clothed body (clothing and exposed skin) also has an impact: $\mathrm{T}_{m r t}$ is much higher for a darkly pigmented person wearing black garments than a white subject in bright clothing $[1,6]$. The $\mathrm{T}_{m r t}$ calculation suggested by Fanger [1] is based on the idea that the entire surroundings of the human body are divided into $\mathbf{n}$ isothermal surfaces which have the following properties: $\mathbf{T}_{i}[\mathrm{~K}]$ are the surface temperatures, $\epsilon_{i}$ are the emission coefficients, and $F_{i}$ are the 


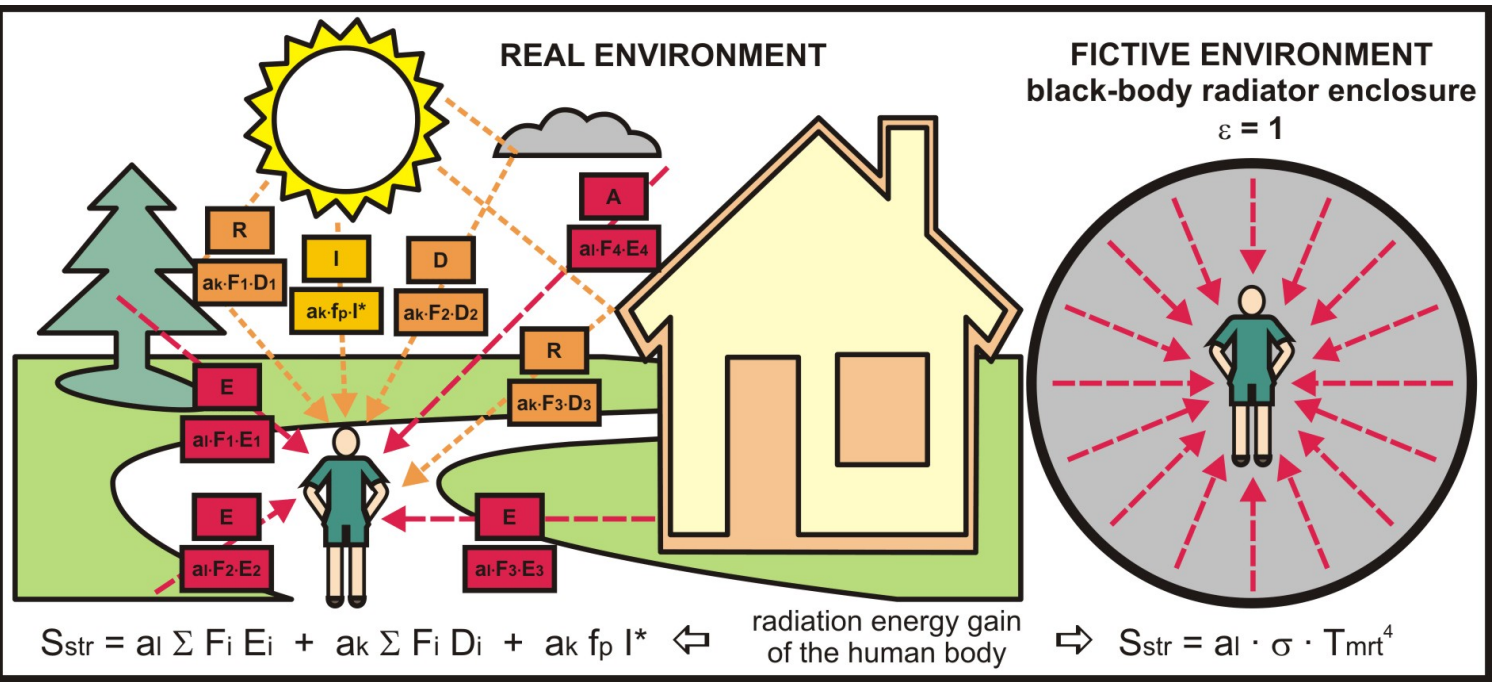

Figure 1. Illustration supporting the understanding of the definition and calculation of the $T_{m r t}$ (explanations of symbols are in the text of this and next sections and in Tables 1,2 and 3).

Table 1. Relevant radiation fluxes and parameters of the human radiation budget (for explanations of symbols see the sections dealing with the definition and calculation of the $\left.\mathrm{T}_{m r t}\right)$.

\begin{tabular}{|l|l|l|l|l|l|}
\hline \multicolumn{2}{|c|}{ Radiation fluxes } & $\begin{array}{l}\text { reaching the } \\
\text { human body }\end{array}$ & $\begin{array}{l}\text { absorbed by the } \\
\text { human body }\end{array}$ & $\mathrm{Q}^{*}$ & $\begin{array}{l}\text { Radiation budget } \\
\text { of the human body }\end{array}$ \\
\hline $\begin{array}{l}\text { solar or short wave } \\
\text { radiation }(\lambda=0.3-3 \mu \mathrm{m})\end{array}$ & $\mathrm{K}$ & & & $\mathrm{K}^{*}$ & short wave budget \\
\hline $\begin{array}{l}\text { direct solar radiation on } \\
\text { a perpendicular surface }\end{array}$ & $\mathrm{I}^{*}$ & $\mathrm{f}_{p} \cdot \mathrm{I}^{*}$ & $\mathrm{a}_{k} \cdot \mathrm{f}_{p} \cdot \mathrm{I}^{*}$ & $\mathrm{I}$ & direct solar radiation \\
\hline $\begin{array}{l}\text { diffuse and } \\
\text { diffusely reflected } \\
\text { short wave radiation }\end{array}$ & $\mathrm{D}_{i}$ & $\Sigma \mathrm{F}_{i} \cdot \mathrm{D}_{i}$ & $\mathrm{a}_{k} \cdot \Sigma \mathrm{F}_{i} \cdot \mathrm{D}_{i}$ & $\mathrm{D}$ & diffuse solar radiation \\
\hline $\begin{array}{l}\text { terrestrial or long wave } \\
\text { radiation }(\lambda=3-100 \mu \mathrm{m})\end{array}$ & $\mathrm{L}$ & & & $\mathrm{R}$ & $\begin{array}{l}\text { reflected short wave radi- } \\
\text { ation }\end{array}$ \\
\hline $\begin{array}{l}\text { long wave radiation of the } \\
\text { environment }\end{array}$ & $\mathrm{E}_{i}$ & $\Sigma \mathrm{F}_{i} \cdot \mathrm{E}_{i}$ & $\mathrm{a}_{l} \cdot \Sigma \mathrm{F}_{i} \cdot \mathrm{E}_{i}$ & $\mathrm{~A}$ & $\begin{array}{l}\text { long wave budget } \\
\text { radiation }\end{array}$ \\
\hline & & & & $\mathrm{E}$ & $\begin{array}{l}\text { environmental long wave } \\
\text { radiation }\end{array}$ \\
\hline
\end{tabular}

"angle factors" describing the solid angle proportions of the mentioned surfaces $(i=1, \ldots, n)$. According to the Stefan-Boltzmann's law, each of these $\mathbf{n}$ isothermal surfaces (ground, surroundings, and also the sky) emits $E_{i}$ $\left[\mathrm{W} / \mathrm{m}^{2}\right]$ long wave radiation:

$$
E_{i}=\varepsilon_{i} \cdot \sigma \cdot T_{i}^{4}
$$

where $\sigma$ is the Stefan-Boltzmann constant $\left(\sigma=5.67 \cdot 10^{-8}\right.$
$\left.\mathrm{W} / \mathrm{m}^{2} \mathrm{~K}^{4}\right)$. On the other hand, these surfaces reflect diffusely the short wave radiation: $D_{i}\left[\mathrm{~W} / \mathrm{m}^{2}\right]$ means the diffuse solar radiation (from the sky) or the diffusely reflected diffuse and direct solar radiation (from the ground and the surroundings). All of the emitted $E_{i}$ long wave and diffusely reflected $D_{i}$ short wave fluxes have to be weighted with the $F_{i}$ angle factors, then summarized in order to determine the energy amounts reaching the human body (Table 1). 
Table 2. Surface projection factor $\mathrm{f}_{p}$ as a function the solar altitude $\gamma$ for a rotationally symmetric standing or walking person [6].

\begin{tabular}{|c|c|c|c|c|c|c|c|c|c|c|}
\hline$\gamma$ & $0^{\circ}$ & $10^{\circ}$ & $20^{\circ}$ & $30^{\circ}$ & $40^{\circ}$ & $50^{\circ}$ & $60^{\circ}$ & $70^{\circ}$ & $80^{\circ}$ & $90^{\circ}$ \\
\hline $\mathbf{f}_{p}$ & 0.308 & 0.304 & 0.292 & 0.271 & 0.237 & 0.205 & 0.174 & 0.140 & 0.108 & 0.082 \\
\hline
\end{tabular}

The other significant short wave component is the direct solar radiation. The radiation intensity of the sun on a surface perpendicular to the incident radiation is marked with $\mathrm{I}^{*}\left[\mathrm{~W} / \mathrm{m}^{2}\right]$. The belonging weighting parameter, the surface projection factor $\mathbf{f}_{p}$ (Table 1), express the portion of body surface exposed to direct solar radiation (Fig. 2). It is a function of the incident radiation direction (solar altitude angle) as well as the body posture (e.g. standing or seated) and orientation. For practical application in human-biometeorological thermal comfort studies, it is generally adequate to determine the surface projection factor for a cylindrical body in an upright posture (Table 2) [6].

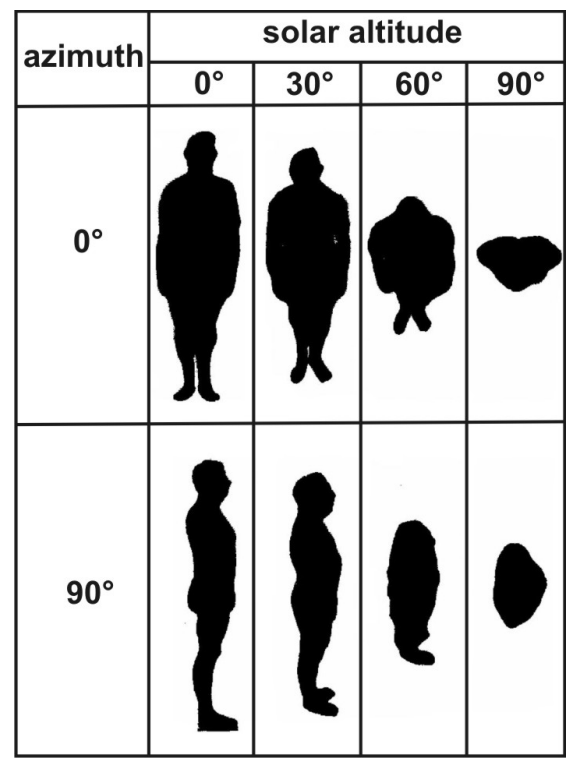

Figure 2. Silhouettes of a standing male corresponding to the areas illuminated by direct solar radiation at different values of solar azimuth and altitude [12].

The energy fluxes reaching the human body are absorbed according to the absorption coefficients $\mathbf{a}_{k}$ for short wave and $\mathbf{a}_{\text {l }}$ for long wave radiation, therefore each of the above mentioned radiation components have to be weighted with them (Table 1). Table 3 contains typical values of the absorption coefficients for human skin and clothing. These are generally assumed to be 0.7 for solar radiation $\left(a_{k}\right)$ and 0.97 for terrestrial radiation $\left(a_{l}\right)$, which equals to the emission coefficient of the clothed human body $\left(\epsilon_{p}\right)$ in pur-
Table 3. Absorption coefficients for long wave and short wave radiation [7].

\begin{tabular}{|c|c|c|c|c|}
\hline \multicolumn{2}{|c|}{ absorption coefficient } & skin & clothing & standard value \\
\hline \hline for long wave radiation & $\mathbf{a}_{l}$ & 0.99 & 0.95 & 0.97 \\
\hline for short wave radiation & $\mathbf{a}_{k}$ & $0.55-0.85$ & $0.4-0.9$ & 0.7 \\
\hline
\end{tabular}

suance of Kirchoff's law.

According to the above mentioned argument, the prevailing radiation fluxes of the real environment $\left(I^{*}, D_{i}, E_{i}\right)$ result in energy gain which is influenced by parameters describing the location and orientation of the person and the radiant sources to each other $\left(F_{i}\right.$ and $\left.f_{p}\right)$, as well as by the absorption coefficients $\left(a_{k}\right.$ and $\left.a_{l}\right)$ of the clothed body surface. Thus, the radiation flux density $\mathrm{S}_{S t r}\left[\mathrm{~W} / \mathrm{m}^{2}\right]$ absorbed by the human body can be described as (compiled by the authors based on $[6,7])$ :

$$
S_{S t r}=a_{l} \cdot \sum_{i=1}^{n} F_{i} \cdot E_{i}+a_{k} \cdot \sum_{i=1}^{n} F_{i} \cdot D_{i}+a_{k} \cdot f_{p} \cdot I^{*} .
$$

According to the definition of $\mathrm{T}_{m r t}$ the radiant energy gain of the human body located in the real environment is equal to that in the fictive environment which is a black-body radiator $(\epsilon=1)$, isothermal enclosure with $\mathrm{T}_{m r t}[\mathrm{~K}]$ temperature. It emits $\sigma \cdot T_{m r t}{ }^{4}$ radiant energy in the long wave radiation range, from which the human body absorbs according to its absorption coefficient $\mathrm{a}_{l}\left(\mathrm{a}_{l}=\epsilon_{p}\right)$ :

$$
S_{S t r}=a_{l} \cdot \sigma \cdot T_{m r t}^{4}=\varepsilon_{p} \cdot \sigma \cdot T_{m r t}^{4} .
$$

Solving the equation for $T_{m r t}$ and substituting the $S_{S t r}$ value calculated in the real environment:

$$
\begin{gathered}
T_{m r t}=\sqrt[4]{\frac{S_{S t r}}{\varepsilon_{p} \cdot \sigma}} \\
T_{m r t}=\sqrt[4]{\frac{\sum_{i=1}^{n} F_{i} \cdot a_{l} \cdot E_{i}}{\varepsilon_{p} \cdot \sigma}+\frac{\sum_{i=1}^{n} F_{i} \cdot a_{k} \cdot D_{i}}{\varepsilon_{p} \cdot \sigma}+\frac{f_{p} \cdot a_{k} \cdot l^{*}}{\varepsilon_{p} \cdot \sigma}} T_{m r t} \\
=\sqrt[4]{\frac{1}{\sigma} \cdot \sum_{i=1}^{n}\left(E_{i}+a_{k} \cdot \frac{D_{i}}{\varepsilon_{p}}\right) \cdot F_{i}+\frac{f_{p} \cdot a_{k} \cdot l^{*}}{\varepsilon_{p} \cdot \sigma}} .
\end{gathered}
$$


If there is no direct solar radiation, the formula is a bit simpler [6]:

$$
T_{m r t}=\sqrt[4]{\frac{1}{\sigma} \cdot \sum_{i=1}^{n}\left(E_{i}+a_{k} \cdot \frac{D_{i}}{\varepsilon_{p}}\right) \cdot F_{i}}
$$

\section{Problems in the course of deter- mination $\mathbf{T}_{m r t}$}

Recording the radiation fluxes, i.e. obtaining the mean radiant temperature in urban settings with complex surface morphology means the largest challenge for the thermal comfort researchers as the flux densities are considerably diverse spatially and temporally. Natural and artificial obstacles, on the one hand, reduce the direct solar radiation depending on their dimensions, structure, orientation, transmittance and the position of the sun. On the other hand, they act as thermal radiators, providing various amount of long wave radiant energy for the human body according to their surface temperature, emissivity, solid angle proportion and the position of the person under consideration.

The main problems in the course of $\mathrm{T}_{m r t}$ calculation are the specification of the surrounding surfaces with their solid angle proportions (angle factors $F_{i}$ ) and the measurement of the individual short and long wave radiation fluxes reaching the human body. In that special case when the human body is situated on a large flat surface without any horizon obstruction, the determination of angle factors is quite simple: the ground represents the lower and the sky the upper hemisphere and consequently both have an angle factor of 0.5 . For these conditions Jendritzky et al. developed a simple method for determining $T_{m r t}$ based on air temperature, cloudiness and solar altitude $[9,10]$.

However, in the case of more complex surface morphology (especially in urban environments) determination of all relevant radiation fluxes and the individual angle factors is very difficult; a theoretically appropriate measurement methodology is discussed in VDI 3789 Part 2 [13]. Direct radiation measurements can be avoided by using $P C$ software to model the 3-dimensional radiation field and to compute $T_{m r t}$. Besides the individual measurement or model based calculation, the $\mathrm{T}_{m r t}$ can be determined also by using integral radiation measurement techniques [6]. From the above mentioned methodological procedures only those which have high relevance in the practice will be presented below. In these techniques urban planners and designers may be interested to estimate the thermal comfort conditions in different urban environments. The first discussed methods of obtaining $T_{m r t}$ are based on integral radiation measurements; one of them applies globe thermometer and the other utilizes the combination of a pyranometer and a pyrgeometer. Then simulation based approaches will follow modelling the radiation environment with PC software RayMan, ENVI-met and SOLWEIG.

\section{Determination of $\mathbf{T}_{m r t}$ by integral radiation measurements}

The simplest method of obtaining $\mathrm{T}_{m r t}$ with integral radiation instruments is based on the utilization of a globe thermometer. Originally, it was developed for indoor applications (e.g. $[14,15])$, but later it has been extended for outdoor measurements (e.g. $[16,17])$. The standard globe thermometer is a flat black-painted hollow copper sphere (diameter is $150 \mathrm{~mm}$, thickness is $0.4 \mathrm{~mm}$ ) with a thermometer bulb at the centre (Fig. 3a). The $\mathrm{T}_{m r t}\left[{ }^{\circ} \mathrm{C}\right]$ is calculated from the measured globe temperature according to the following equation:

$$
T_{m r t}=\sqrt[4]{\left(T_{g}+273.15\right)^{4}+\frac{h_{C g}}{\varepsilon \cdot d_{g}^{0.4}} \cdot\left(T_{g}-T_{a}\right)}-273.15
$$

where $\mathrm{T}_{g}\left[{ }^{\circ} \mathrm{C}\right]$ is the globe temperature, $\mathrm{T}_{a}\left[{ }^{\circ} \mathrm{C}\right]$ is the air temperature, $\epsilon$ is the emissivity of the sphere $(=0.95$ for a black globe), $\mathbf{d}_{g}[\mathrm{~mm}]$ is the diameter of the sphere, and $\mathbf{h}_{C g}$ is the globe's mean convection coefficient. The latter is a function of the wind velocity $\mathrm{v}_{a}[\mathrm{~m} / \mathrm{s}]$, and also consists of an empirical derived parameter which depends on the characteristics of the globe $[18,19]$ :

$$
h_{C g}=1.1 \cdot 10^{8} \cdot v_{a}^{0.6}
$$

In effect, the temperature value measured in the centre of the globe at equilibrium results from heat exchange processes through radiation and also through convection, so the $\mathrm{T}_{g}$ represents the weighted average of the $\mathrm{T}_{m r t}$ and the $\mathrm{T}_{a}$. The stronger the air movement is, the closer is the value of $\mathrm{T}_{g}$ to $\mathrm{T}_{a}$, and $\mathrm{T}_{g}$ equals the $\mathrm{T}_{m r t}$ only in calm conditions. The cooling effect of the wind i.e. the role of the convective heat loss can be reduced by a bigger thermometer bulb, but it would significantly increase its response time.

The globe thermometer i.e. the measured $\mathrm{T}_{g}$ gives a good approximation of $T_{m r t}$ indoors where the radiant heat fluxes from the surrounding surfaces are rather uniform. Although it is relatively cheap and enables simple mobile measurements, in outdoor cases, where the radiant environment is not homogeneous, it is less suitable for several reasons $[11,19]$ : 


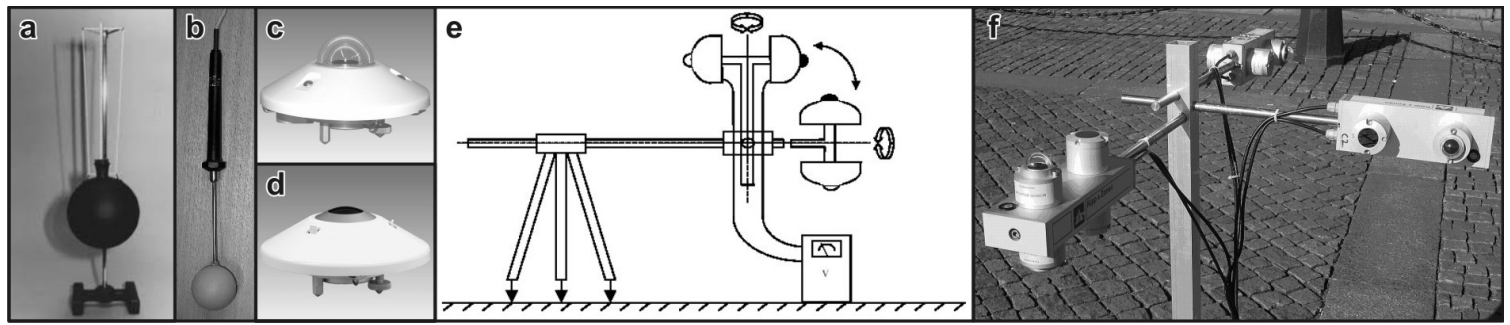

Figure 3. Integral radiation measurements: (a) a standard globe thermometer and (b) a flat grey globe thermometer constructed for outdoor thermal comfort studies $[18,19]$, in addition (c) a pyranometer, (d) a pyrgeometer (e) a radiation instrument containing a rotatable combination of them [6], as well as (f) three net radiometers oriented to measure radiation fluxes from six perpendicular directions at the same time $[18,19]$.

1. The spherical shape averages the absorbed radiation equally from all directions, so the globe thermometer enables a good approximation for the human body in seated posture, but not for a standing person (as at this posture the lateral radiation fluxes are dominant).

2. The $T_{m r t}$ calculation from this integral radiation measurement by globe thermometer assumes equally absorbed radiation energy in both the long and short wave domain, and it does not consider that the black colour of the sphere overestimates the absorption in the short wave range.

3. The response time of the globe thermometer is too long for outdoor investigations: it takes up to 1520 minutes to reach the equilibrium. Normally, the $\mathrm{T}_{a}$ and $\mathrm{v}_{a}$ change more quickly outdoors, meaning that equilibrium is never reached and the calculated $\mathrm{T}_{m r t}$ value becomes uncertain.

To solve the problem of uncertainty due to the longer response time, the size of the sphere should be reduced; then the equilibrium is reached more quickly. However, in that case the relative effect of the convective heat exchange increases and the final $T_{g}$ is affected less by radiation; i.e. the accuracy of the obtained $T_{m r t}$ becomes poorer. An optimal sphere-diameter may balance between the accuracy and the uncertainty (response time) of the measurement. The problem derived from the black colour can be avoided by using a grey globe, because the lighter colour is more suitable to represent the radiant properties of the skin and the general clothing of a person. For example, $[18,19]$ used a Pt100 sensor placed in the centre of a flat gray painted hollow acrylic sphere with a diameter of $38 \mathrm{~mm}$ and a thickness of $1 \mathrm{~mm}$ (Fig. 3b). This globe thermometer had a response time less than 5 minutes, and with simultaneous $\mathrm{T}_{a}$ and $\mathrm{v}_{a}$ measurements it has proven to be an accurate device to assess the $\mathrm{T}_{m r t}$ outdoors. The grey globe thermometers need outdoor validation before
Table 4. Weighting factors $W_{i}$ depending on the shape and orientation [7].

\begin{tabular}{|c|c|c|c|c|c|c|}
\hline & East & South & West & North & upward & downward \\
\hline \hline standing person & 0.220 & 0.220 & 0.220 & 0.220 & 0.060 & 0.060 \\
\hline seated person & 0.185 & 0.185 & 0.185 & 0.185 & 0.130 & 0.130 \\
\hline globe & 0.167 & 0.167 & 0.167 & 0.167 & 0.167 & 0.167 \\
\hline
\end{tabular}

the measurements in order to determine the globe's mean convection coefficient $\mathrm{h}_{C g}$ depending on the material and dimensional characteristics of the sphere.

The most accurate method of $\mathrm{T}_{m r t}$ determination in outdoor settings (suggested also by the VDI 3789 guideline) is the measurement technique proposed by Höppe [7]. However, due to the required equipment, this is also the most costly and complicated approach of obtaining $T_{m r t}$ in practice. The solar and terrestrial radiation fluxes reaching the human body are measured separately; pyranometer (Fig. 3c) is used to record the radiation fluxes from the respective half-space (hemisphere) in the short wave and pyrgeometer (Fig. 3d) in the long wave domain. The environment is divided into six main parts according to the four cardinal points of the compass and to the upper and lower directions. These perpendicular directions represent the 3-dimensional radiation field and each of them has different weighting factors according to the shape of the body under consideration (Table 4).

The mean radiation flux density $\mathrm{S}_{\text {str }}\left[\mathrm{W} / \mathrm{m}^{2}\right]$ absorbed by the body is calculated from the measured six individual solar $\mathrm{K}_{i}\left[\mathrm{~W} / \mathrm{m}^{2}\right]$ and terrestrial $\mathrm{L}_{i}\left[\mathrm{~W} / \mathrm{m}^{2}\right]$ fluxes, which have to be multiplied by the weighting factors $\mathbf{W}_{i}$ corresponding to the direction of the measurements ( $i=1$ to 6 ) as well as by the absorption coefficients of the clothed body for short wave $\mathbf{a}_{k}$ and long wave $\mathbf{a}_{l}$ radiation (Tables 3 and 4) [7]:

$$
S_{S t r}=\sum_{i=1}^{6} W_{i} \cdot\left(a_{k} \cdot K_{i}+a_{l} \cdot L_{i}\right)
$$


Then the $\mathrm{T}_{m r t}\left[{ }^{\circ} \mathrm{C}\right]$ is calculated from the absorbed radiation flux density $\mathrm{S}_{\text {str }}$ according to the Stefan-Boltzmann's law:

$$
T_{m r t}=\sqrt[4]{\frac{S_{S t r}}{\varepsilon_{p} \cdot \sigma}}-273.15
$$

where, $\sigma$ is the Stefan-Boltzmann constant and $\varepsilon_{p}$ is the emissivity of the clothed human body which is equal to $\mathrm{a}_{l}$ according to Krichhoff's law. The main advantage of this probe is the separate measurement of the short and long wave radiation, which allows consideration of the different absorption coefficients. This is crucially, as $a_{l}$ is set to 0.97 while the value of $a_{k}$ is only 0.7 meaning that the long wave fluxes have relatively greater importance.

If only one pyranometer-pyrgeometer pair is used, they have to be mounted on a horizontally and vertically rotatable instrument at the height of $1.1 \mathrm{~m}$ above the ground which represents the place of the weighting centre of the standing human body. By turning the sensors through $90^{\circ}$ in each case, e.g. into the four lateral directions as well as downward and upward, it is possible to measure the radiation fluxes from the 3-dimensional radiation field (Fig. 3e). As the response time of the sensors has to be taken into account (ca. 3 minutes in the case of each stand of the instrument), a whole measurement period takes $18 \mathrm{~min}-$ utes. This time can be decreased to 9 minutes by using a rotatable net radiometer consisting of 2 pyranometers and 2 pyrgeometers facing in the opposite directions. The calculated $\mathrm{T}_{m r}$ has 3-minute temporal resolution in both cases. It is possible to avoid the procedure of rotation if the radiation flux densities from the six directions are measured at the same time. This however, requires three, perpendicularly oriented net radiometers, which makes the measurement technique quite expensive (Fig. 3f).

\section{Calculation of the $\mathbf{T}_{m r t}$ by mod- elling the whole radiation field}

Without sophisticated and time-consuming field measurement procedures, the individual radiation fluxes can be obtained by model approaches applying easily accessible input meteorological parameters, such as air temperature, air humidity, degree of cloud cover, and air clarity (atmospheric turbidity) $[6,20,21]$. In addition to the atmospheric variables, temporal parameters (day of the year and time of the day) as well as the geographical location must be specified. Modelling radiant fluxes in urban environments definitely needs data about the artificial and natural obstacles reducing the visible portion of the sky (can be described with the sky view factor). Application of a correct surface morphological database containing geometrical properties of buildings and vegetation in the study area is the most critical part of the modelling procedure. Beyond the solid angle proportions (i.e. view factors) of the different surrounding obstacles, some of their measures, significant from the point of view of radiant energy exchange need also be specified: albedo, transmissivity and emissivity. All of the above mentioned environmental parameters together with the radiant properties of the human body (such as emissivity and absorbance) have to be known in order to calculate the mean radiant temperature $[6,20,21]$. Several different models (software) have been developed in the recent years with the aim of simulating the 3-dimensional radiation field in urban settings and calculate the $\mathrm{T}_{m r t}$.

Due to its user-friendly interface, the very fast running time and because it is freely available, RayMan is one of the most popular tools for thermal comfort researchers, and urban planners $[20,21]$. This radiation and bioclimate model has been developed based on the VDI-Guidelines 3789 and $3787[6,13]$. RayMan divides the 3-dimensional environment into an upper and a lower hemisphere with a parting plane between them at $1.1 \mathrm{~m}$ above the ground, at the height of the weighting centre of a standing human body. The model simulates the radiation flux densities and calculates the $T_{m r t}$ based on the following information:

1. Temporal specification: date i.e. day of the year as well as time of the day.

2. Geographical location: longitude, latitude, altitude, time zone.

3. Meteorological input: air temperature, air humidity (vapour pressure or relative humidity), global radiation (or cloud cover at least), moreover the turbidity, the Bowen-ratio and the ratio of diffuse and global radiation. One of the main advantages of RayMan from the point of view of $\mathrm{T}_{\text {mrt }}$ calculation is that the required meteorological data are easy to obtain and have no high spatial variability.

4. Information about horizon limitation: RayMan offers many options to enter the data on complex horizons which modify the radiation field:

(a) Topographical data can be edited or created in order to limit the horizon by topographical effects.

(b) Surface morphological input: detailed spatial data (coordinates and dimensions) and radiation properties of the obstacles locating in the investigated area: 
i. data about buildings: (relative) coordinates, length, width, height, emissivity and albedo;

ii. data about vegetation: (relative) coordinates, type of the tree (deciduous or coniferous), full height and trunk height, radius of canopy, emissivity and albedo.

This database can be edited graphically as well as numerically and each kind of the 3dimensional obstacles can be switched on and off with regard to the RayMan calculations.

(c) The RayMan considers also other input possibilities of horizon limitation beyond the topographical and surface morphological data. If there are no detailed 3D data sets about the research area it is possible to draw "horizon limitation polygon" freely in a fish-eye viewed grid map, as well as according to imported fish-eye photos [19-21].

The model serves other useful outcomes beyond the $T_{m r t}$ :

1. Sun paths for any day of the year can be shown graphically in a fish-eye view.

2. Shadowed areas generated by the obstacles can be presented on a grid map for each day of the year and for each specific period of the day.

3. Sunshine duration with and without horizon limitation can be calculated in daily resolution.

4. Thermal comfort indices PMV [1], SET* [22], PET [23] and UTCI [8] can be calculated, which makes the model suitable for human bioclimatological assessments not only on the radiation field but also in a wider sense. RayMan is able to treat $T_{m r t}$ also as an input parameter for index calculations, if it is determined formerly from site-specific radiation data (e.g. by field measurements with pyranometerpyrgeometer technique).

RayMan is a stationary model compatible with Microsoft Windows and can be used for human bioclimate studies in different time and spatial scales. By using the software, radiation and thermal comfort conditions can be analyzed for complex urban structures and other type of landscapes $[20,21]$. However, the simulations refer only to one point of the investigated area and do not provide a continuous surface of the obtained values, because it would considerably increase the running time.

Such is the case with the 3-dimensional, grid-based ENVI-met model which, on the other hand calculates wind flow, turbulence, temperature, humidity as well as radiation fluxes and $\mathrm{T}_{m r t}$ with high spatial (0.5-10 $\mathrm{m}$ horizontally) and temporal (up to $10 \mathrm{~s}$ ) resolution [24-26]. This microclimate model has been designed based on the fundamental laws of fluid and thermodynamics to simulate the surface-plant-air interactions in urban settings for purposes of urban climatology, architecture, urban design and planning. The software can be run on a regular PC with Microsoft Windows.

In order to represent the difficult urban environment with complex surface morphology, the software makes it possible to build up a detailed 3D model domain (max. $250 \times 250 \times 25$ grids) containing:

1. Buildings in multifarious arrangements with different heights, shapes and designs.

2. Vegetation with specific properties: different types (tree, bush, grass), height, dense of foliage. Trees are handled, on the one hand, as porous obstacles to wind and solar radiation, on the other hand, they contain also physiological processes (evapotranspiration and photosynthesis).

3. Different soil types consisting of several layers.

The non-stationary, non-hydrostatic ENVI-met predicts all of the exchange processes and simulates all of the microclimatic parameters within a daily cycle for each grid of the model domain. The huge number of output variables and the fine resolution in time and space necessitate the long running time for model calculations; it often takes up several days $[11,24-26]$.

Both the above mentioned models calculate $\mathrm{T}_{m r t}$ at street level (RayMan calculates to one point and ENVI-met to a surface) according to Fanger's [1] idea. The surroundings are divided into many sections (free atmosphere, several building surfaces and also the ground surface) for which the direct, diffuse and diffusely reflected short wave and the emitted long wave radiation components are taken into account. The long wave fluxes at street level are assumed to originate as $50 \%$ from the upper hemisphere (sky and buildings) and 50\% from the ground (lower hemisphere) $[11,27]$. However, in complex urban environments the long wave radiation absorbed by the standing body originates mainly from the surrounding walls; thus for better estimation of $\mathrm{T}_{m r t}$ it is important to take into consideration the lateral directions.

The SOLWEIG (solar and long wave environmental irradiance geometry-model) calculates the $T_{m r t}$ on the basis of the integral radiation measurement procedure introduced by [7] so it considers the solar and terrestrial radiation flux densities from 6 perpendicular directions $[27,28]$. The SOLWEIG simulates spatial variations of radiation fluxes, $\mathrm{T}_{m r t}$ and shadow patterns in urban environments based 
on geographical information (longitude, latitude, altitude), surface morphology and simple meteorological parameters including direct, diffuse and global shortwave radiation, air temperature and relative humidity. (In contrast to the first version, SOLWEIG 2.0 also enables the modelling of direct and diffuse components of short wave radiation.) The complex urban surface morphology in SOLWEIG is represented by high-resolution digital elevation models (DEMs). SOLWEIG can be considered as a 2.5dimensional $\mathrm{T}_{m r t}$ model as the applied input DEMs are 2.5-dimensionals containing $x$ and $y$ coordinates with height attributes, while the results are 2-dimensional having only horizontal $x, y$ extensions and referring at the height of $1.1 \mathrm{~m}$. SOLWEIG 1.0 included only an urban raster DEM to account for ground and buildings but in the second version the trees (coniferous or deciduous trees) and bushes are also represented. For this purpose two new DEMs have been introduced: one for the canopy and another for the trunk zone (bushes have no trunk zone). As human activities take place in the trunk zone, considering this area in the course of modelling radiation fluxes is very important; especially at high geographical latitudes or low Sun elevation, when the trunk zone may receive relatively greater solar radiation from a lateral direction [28].

SOLWEIG is able to handle very large model domains meaning more than $1,000 \times 1,000$ pixels on a regular $P C$. The simulated $\mathrm{T}_{m r t}$ and shadow patterns have hourly temporal resolution which would be improved in the future. Similarly to the above mentioned two models, SOLWEIG also has a user-friendly graphical interface. The other great advantage of the model is that it also copes with low sun elevation angles, which cause problems when using the RayMan software $[27,28]$.

\section{Discussion}

The mean radiant temperature is one of the key factors governing human thermal comfort in urban environments, and due to the complex radiant geometry in cities, it is also the most unsteady input parameter for index calculations. It can be obtained through several different ways, but urban climatologists, architects and urban planners ask for reliable and simple tools for estimating of $\mathrm{T}_{m r t}$.

The most adequate procedure for obtaining $T_{m r t}$ experimentally is the use of a radiation instrument consisting of pyranometer and pyrgeometer which have to be orientated in six directions. This technique has the advantage, that solar and terrestrial radiation fluxes are measured separately, consequently the different absorption coefficients of the clothed human body to short and long wave radiation can be considered. However, this method is quite complex and expensive, especially if the measurement of the relevant short and long wave radiation fluxes from the six directions is solved at the same time with three net radiometers. The other opportunity, which works with a rotatable combination of a pyranometer and a pyrgeometer, is very time-consuming (Fig. 3).

A more rapid and less expensive way for estimating the $\mathrm{T}_{m r t}$ is based on field measurements using a globe thermometer constructed for outdoor application with simultaneously conducted air temperature and wind velocity measurements. The grey globe thermometers are however not standard measurement devices, so before the planned field measurements, they have to be validated with a simultaneously conducted pyranometer-pyrgeometer as this technique is the most appropriate way to determine $T_{m r t}$ outdoors [19].

As in most cases continuous monitoring and power sources for the integral radiation equipments are not available, the mentioned field measurements can not be applied in long-term studies. For that reason, it is necessary to work also with PC programs being able to estimate the 3-dimensional radiation environment with all the relevant solar and terrestrial fluxes and then calculate $\mathrm{T}_{m r t}$. One of the main advantages of such models is the possibility of testing the micro-bioclimatic effects of different planning scenarios by modifying the dimensions, arrangements, and the radiant properties of the buildings and the vegetation in the model environment [20].

The models always contain some physical assumptions with respect to the following obstacle-attributes: surface temperatures and emissivity (which are required for the calculation of long wave emission), albedo (necessary to determine the reflected part of short wave radiation) as well as transmittance for short and long wave radiations. The values which are selected for these measures (as default values and treated as constant) are usually from different tables and not from field measurements, thus they may not be representative. Besides, the modeled building and vegetation elements are usually simplified shapes compared to the real obstacles.

As all of the presented simulation tools have numerous beneficial as well as unfavourable features, the users have to decide which model fits the best for their purposes. Based on the results of $[20,21]$ the correlations between measured (pyranometer-pyrgeometer probe) and RayMan-simulated $\mathrm{T}_{m r t}$ values are strong $(\mathrm{r}=0.95$ for a semi-open place and $r=0.96$ for under a tree in the Central European city of Freiburg). However, RayMan tends to underestimate $\mathrm{T}_{m r t}$. According to Thorsson et al. [19] this underestimation is particularly obvious at low solar elevations (based on measurements and simulations performed in the high latitude city of Göteborg). The SOLWEIG-based $\mathrm{T}_{m r t}$ seems to be more reliable at low sun altitude, as the radiation fluxes are not only considered 
for horizontal surfaces, but also from the four vertical directions. The model showed a good performance: there is almost a one to one relationship between the modeled and measured data (based on observations carried out in Göteborg, Kassel and Freiburg) and the corresponding correlation coefficient is $0.96[27,28]$. Ali-Touder [11] found that ENVI-met was suitable to show the different trends of $\mathrm{T}_{m r t}$ in the case of day and night; however, this model significantly overestimated $\mathrm{T}_{m r t}$ during the morning hours and underestimated it from noon and throughout the night. The ENVI-met and the SOLWEIG serve 2-dimensional outputs, while the RayMan calculations refer only to one point which means the model is also significantly faster to run. All of the presented models handle not only the buildings, but simulate the radiant modifying effects of the vegetation too.

It has to be emphasized again, that the modelling procedure always means simplification, especially in landscapes with diverse surface morphology. Therefore, the model simulations concerning the radiation and bioclimatic conditions of real urban environments have to be supported with field measurements obtaining $\mathrm{T}_{m r t}$ and thermal indices experimentally. Modelling the short and long wave radiation components from the free sky presents no difficulty, but the reflected solar and emitted terrestrial fluxes from the solid surfaces cause more problems in morphologically complex urban environments. It is not yet solved perfectly in the presented models how the inclined or vertical surfaces affect the 3-dimensional radiation field. Moreover, there are some other parameters whose assessments have to be improved; e.g. the quantification of the clouds or the estimation of atmospheric turbidity [20]. Due to the argumentation above, all of the discussed models are under continuous development or improvement.

\section{Conclusion}

Because of the rapidly growing global population and the better working possibilities in cities, more and more people have to live or work in urban areas. These citizens are affected by many forms of strain inherent to the life within towns; i.e. various kinds of air pollution, odours, noise, light pollution, exhaustion due to the accelerated lifestyle and last but not least thermal stress. For the improvement of their life it is essential the collaboration between the urban planning and disciplines aiming to study human comfort conditions in cities. One of these disciplines is urbanbiometeorology, which deals with the effects of weather conditions, climate and air quality on human beings in urban environment $[5,6]$. Human-biometeorological studies describe the thermal component of the urban climate in a thermo-physiologically significant manner, i.e. they estimate the combined effects of air temperature, air hu- midity and wind velocity as well as short- and long wave radiation on the human thermoregulatory system. This is an important task because thermal comfort conditions affect the efficiency, well-being and also the health conditions of people [29].

In order to communicate successfully with urban planners and designers it is important to use measures bearing comprehensive, thermo-physiologically significant information; but also which are easy to understand. Wellknown indices in the practice are the Predicted Mean Vote (PMV) derived from Fanger's comfort equation [1], the Standard Effective Temperature (SET*) from Gagge's two-node model $[22,30]$ and the Physiologically Equivalent Temperature (PET) obtained from the Munich Energy balance Model for Individuals (MEMI) [3, 23, 31]. The newest measure in this field is the Universal Thermal Climate Index based on Fiala's multi-node model [8]. Such indices can be used to characterize thermal comfort conditions evolved in existing urban structures, and to clarify whether certain urban planning scenarios would maintain, improve or worsen the human-biometeorological situation. As the thermal conditions in urban micro-environments in summer are determined mainly by the varied radiation field, the $T_{m r}$, as a basic input of all of the mentioned indices, deserves much more attention than the less variable air temperature. Therefore, this paper aimed to overview the theoretical background and the practical opportunities for determination of this problematic parameter.

\section{Acknowledgements}

This work was supported by the Hungarian Scientific Research Fund (OTKA K-67626) and by the "TÁMOP4.2.1/B-09/1/KONV-2010-0005 - Creating the Center of Excellence at the University of Szeged".

\section{References}

[1] Fanger P.O., Thermal Comfort. McGraw Hill placeCityBook, StateNew York, country-regionUSA, 1972

[2] Mayer H., Höppe P., Thermal comfort of man in different urban environments. Theor. Appl. Climatol., 1987, 38, 43-49

[3] Höppe P., Heat balance modelling. Experientia, 1993, 49, 741-746

[4] Jendritzky G., The atmospheric environment - an introduction. Experientia, 1993, 49, 733-738

[5] Mayer H., Urban bioclimatology. Experientia, 1993, 49, 957-963

[6] VDI, Methods for the human-biometeorological assessment of climate and air hygiene for urban and 
regional planning. Part I: Climate. VDI 3787, Part 2. Beuth, Berlin, 1998

[7] Höppe P., Ein neues Verfahren zur Bestimmung der mittleren Strahlungstemperatur in Freien. [A new measurement procedure to obtain the mean radiant temperature outdoors]. Wetter und Leben, 1992, 44, 147-151 (in German)

[8] official Universal Thermal Climate Index (UTCI) website: www.utci.org

[9] Jendritzky G., Sönning W., Swantes H.J., Ein objektives Bewertungsverfahren zur Beschreibung des thermischen Milieus in der Stadt- und Landschaftsplanung (Klima-Michel-Modell) [An objective assessment procedure to specify the thermal environment in urban and landscape planning]. Beltrage der Akademie für Raumforschung und Landesplanung, 1979, 28, 85p (in German)

[10] Jendritzky G., Nübler W., A model analysing the urban thermal environment in physiologically significant terms. Arch. Met. Geoph. Biokl., 1981, Ser. B, 29, 313-326

[11] Ali-Toudert F., Dependence of the outdoor thermal comfort on street design in hot and dry climate. Berichte des Meteorologischen Institutes der Universität Freiburg, 2005, 15, 1-229

[12] Underwood C.R., Ward E.J., The solar radiation area of man. Ergonomics, 1966, 9, 155-168

[13] VDI, Environmental meteorology, interactions between atmosphere and surface; Calculation of shortand long wave radiation. Part I: Climate. VDI 3789, Part 2. Beuth, Berlin, 1994

[14] Vernon H.M., The measurement of radiant temperature in relation to human comfort. Journal of Industrial Hygiene, 1932, 14, 95-111

[15] Bedford T., Warner C.G., The globe thermometer in studies of heating and ventilation. Journal of Instrument Hygiene, 1934,34, 428-432

[16] Clarke J.F., Bach B., Comparison of the comfort conditions in different urban and suburban microenvironments. Int. J. Biometeorol., 1971, 15, 41-54

[17] Nikolopoulou M., Baker N., Steemers K., Thermal comfort in outdoor urban spaces: Understanding the human parameter. Sol. Energy 2001, 70, 227-235

[18] Thorsson S., Lindberg F., placeSnEliasson Snl., Holmer B., Measurements of mean radiant temperature in different urban structures. In: Lindqvist $\mathrm{S}$., Grimmond C.B.S. (Eds), Proceedings of the 6th Int. Conf. on Urban Climate, Göteborg University, Sweden, 2006, 867-870

[19] Thorsson S., Lindberg F., Holmer B., Different methods for estimating the mean radiant temperature in an outdoor urban setting. Int. J. Climatol., 2007, 27, 1983-1993
[20] Matzarakis A., Rutz F., Mayer H., Modelling radiation fluxes in simple and complex environments - application of the RayMan model. Int. J. Biometeorol., 2007, 51, 323-334

[21] Matzarakis A., Rutz F., Mayer H., Modelling radiation fluxes in simple and complex environments: basics of the RayMan model. Int. J. Biometeorol., 2010, 54, 131-139

[22] Gagge A.P., Fobelets A.P., Berglund L.G., A standard predictive index of human response to the thermal environment. American Society of Heating, Refrigerating, and Air-Conditioning Engineers Transactions, 1986, 92, 709-731

[23] Höppe P., The physiological equivalent temperature - an universal index for the biometeorological assessment of the thermal environment. Int. J. Biometeorol., 1999, 43, 71-75

[24] Bruse M., Anwendung von mikroskaligen Simulationsmodellen in der Stadtplanung. In: Bernhard L., Küger T. (Eds.), Simulation raumbezogener Prozesse: Methoden und Anwendung [Application of microscale simulation models in urban planning]. Münster, 2000 (in German)

[25] Bruse M., Stadtgrün und Stadtklima - Wie sich Grünflächen auf das Mikroklima in Städten auswirken [Urban green and urban climate â€Ș impacts of the green spaces on the urban microclimate]. LÖBFMitteilungen, 2003, 1, 66-70 (in German)

[26] official ENVI-met website: www.envi-met.com

[27] Lindberg F., Holmer B., Thorsson S., SOLWEIG 1.0 Modelling spatial variations of $3 \mathrm{D}$ radiant fluxes and mean radiant temperature in complex urban settings. Int. J. Biometeorol., 2008, 52, 697-713

[28] Lindberg F., Grimmond C.S.B., The influence of vegetation and building morphology on shadow patterns and mean radiant temperatures in urban areas: model development and evaluation. Theor. Appl. Climatol., DOI 10.1007/s00704-010-0382-8

[29] Mayer H., Holst J., Dostal P., Imbery F., Schindler D., Human thermal comfort in summer within an urban street canyon in Central Europe. Meteorol. Z., 2008, 17, 241-250

[30] Gagge A.P., Stolwijk J.A.J., Nishi Y., An effective temperature scale based on a simple model of human physiological regulatory response. American Society of Heating, Refrigerating, and Air-Conditioning Engineers Transactions, 1971, 77, 247-262

[31] Höppe P., Die Energiebalanz des Menschen[The human heat balance]. Dissertation. Wissenschaftlicher Mitteilung of Universität München, 49, 1984, 171p (in German) 